\title{
Who Falls Between the Cracks? Identifying Eligible PrEP Users Among People With Sub-saharan African Migration Background Living in Antwerp, Belgium
}

\section{Buffel Veerle ( $\nabla$ Veerle.buffel@uantwerpen.be )}

Univerisity of Antwerp, Department of Sociology, Antwerp, Belgium; 2Institute of Tropical Medicine, Department of Public Health, Antwerp, Belgium https://orcid.org/0000-0001-6602-9525

\section{Caroline Masquillier}

Universiteit Antwerpen

\section{Thijs Reyniers}

Instituut voor Tropische Geneeskunde

Ella Van Landeghem

Instituut voor Tropische Geneeskunde

\section{Edwin Wouters}

Universiteit Antwerpen

\section{Bea Vuylsteke}

Instituut voor Tropische Geneeskunde

\section{Christiana Nöstlinger}

Instituut voor Tropische Geneeskunde

\section{Research article}

Keywords: Pre-exposure prophylaxis (PrEP), HIV prevention, Sub-Saharan African (SSA) migrants, eligibility criteria, HIV risk factors

Posted Date: September 24th, 2020

DOI: https://doi.org/10.21203/rs.3.rs-69936/v1

License: (c) (i) This work is licensed under a Creative Commons Attribution 4.0 International License. Read Full License 


\section{Abstract}

Background: This study estimates the proportion of eligible PrEP users among people of Sub-Saharan African background based on the Belgian PrEP eligibility criteria and examines associations with socio-economic and demographic characteristics.

Methods: We performed logistic regression analysis on data of a representative community-based survey conducted among sub-Saharan African communities ( $n=686)$ living in Antwerp.

Results: Almost a third (30.3\%) of the respondents were eligible to use PrEP. Those who were male, single, lower educated, undocumented, and had experienced forced sex were more likely to be eligible for PrEP use. The findings highlight the importance of taking intra-, interpersonal and structural HIV risk factors into account.

Conclusions: The study shows high unmet PrEP needs in this population, especially among those with high vulnerability for HIV acquisition. A better understanding of barriers to PrEP use in this population group is needed to allow for equitable access.

\section{Background}

People with a Sub-Saharan Africa (SSA) migration background are the second largest group affected by HIV in Belgium (1). They constituted $44 \%$ of all new HIV cases with heterosexual transmission mode in $2018,68 \%$ among them were women. An HIV prevalence study among SSA communities in Antwerp found an prevalence of $5.9 \%$ among women and $4.2 \%$ among men (1). About one in three people in this population was estimated to have acquired HIV post-migration in European host countries (2-4). This supports the notion that primary HIV prevention should be strengthened in this group.

Several countries, including Belgium, have taken up Pre-exposure Prophylaxis (PrEP) into their public health response to HIV by reimbursing it for people at high risk of HIV acquisition $(5,6)$. Most countries have developed specific criteria to regulate access to PrEP. In Belgium, national eligibility criteria provide both specific criteria targeting men who have sex with men (MSM) and general criteria for people at high-risk of HIV acquisition (see Box 1). However, PrEP uptake has not been equal across these two groups and currently mainly MSM are using PrEP. In 2017-2018, 98\% of the PrEP starters in Belgium were MSM (7).

Box 1: Eligibility criteria for PrEP reimbursement in Belgium (issued by the National institute for Health and Disability Insurance as of June 1, 2017)

\section{Risk factors allowing for reimbursement}

I. MSM (men who have sex with men):

- who have had condomless anal sex with at least 2 partners in the last 6 months

- who have had multiple Sexually Transmitted Infections (STIs) (Syphilis, Chlamydia, Gonococcus or a primary infection with hepatitis B or C) during the last year

- who needed Post exposure Prophylaxis (PEP) several times during the last year

- who use psychoactive substances during sexual activities.

II. High-risk persons:

- People who inject drugs (PWID) who share needles

- People in sex work who are exposed to condomless sex 
- People in general who are exposed to condomless sex with a high risk of HIV infection

-Partners of people living with HIV (PLWH) without viral suppression (recently started on treatment or no viral suppression with adequate treatment)

Source: Rijksinstituut voor ziekte - en invaliditeitsverzekering (http://www.inami.fgov.be/nl/themas/kost-terugbetaling/doorziekenfonds/geneesmiddel-gezondheidsproduct/terugbetalen/specialiteiten/wijzigingen/Paginas/geneesmiddelen-PrEp-

HIV.aspx\#.WqErnaOzU3E).

The high HIV prevalence among SSA communities found in Antwerp suggests that many people belonging to this group could meet these eligibility criteria and thus benefit from PrEP (8). However, only $1.1 \%$ of all applications for PrEP reimbursement stemmed from people with SSA background (equaling 26 people, of whom 22 were MSM) (7). Research in neighboring countries, such as France, also found barriers to PrEP use among sub-Saharan immigrants $(9,10)$.

We currently do not know what proportion of SSA communities may be eligible for PrEP, because they have been largely overlooked in PrEP research (11). The absence of specific eligibility criteria may prevent healthcare providers from targeting those at risk of HIV acquisition for PrEP or PrEP referral (12). Research has shown that ethnic minority groups at risk of HIV acquisition may not address their prevention needs spontaneously with healthcare providers due to social desirability, discomfort with sharing sensitive information and fear of provider judgement or stigma (12). In addition, HIV prevention demand has found to be generally low among SSA communities and other factors such as insufficient knowledge and misconceptions about PrEP may prevent them from accessing PreP (13, 14).

Against this background, the study objectives are twofold: First, we aim to identify the proportion of SSA migrants who are theoretically eligible for PrEP use, based on the eligibility and reimbursement criteria in Belgium; second, we examine the socio-economic and demographic characteristics that are related to these criteria among SSA migrants. This evidence is relevant to guide health care providers in accurately assessing HIV risk and potential PrEP needs among people of SSA origin.

\section{Methods}

\section{TOGETHER study}

We performed a secondary analysis of data from a representative community-based bio-behavioral cross-sectional survey (i.e. TOGETHER study) to assess HIV prevalence, conducted in 2013-2014 in Antwerp (1). These data are the most recent behavioral data available for this sub-population in Belgium. The study used a two-stage timelocation sampling to obtain a venue-based sample of $n=744$ adult sub-Saharan African migrants in Antwerp. All individuals present in a given setting at the time of the study visit (available attendance data) were included in the survey if they met the following criteria $(n=726)$ : (1) self-identified sub-Saharan African migrant; (2) age 18 years or above; (3) accepting to answer the questionnaire; (4) accepting to provide an oral fluid sample; and (5) providing written informed consent. Recruitment, data collection and weighting procedures to adjust for unequal selection probability are described in detail elsewhere $(1,15)$. For the current analysis, HIV positive participants were excluded (32 HIV positive out of 718 respondents with valid information about their HIV status), since they would not be eligible for PrEP (6).

\section{Operationalization of the eligibility criteria}


The main variables of interest are variables corresponding to the Belgian PrEP eligibility criteria (see Box 1). As specific criteria for people with SSA migrant background are lacking, we adapted both the MSM-specific and general criteria to the target population of this study (Box 2). As not all Belgian PrEP eligibility criteria could be measured directly, proxies were used approaching the original criteria as much as possible. These were developed based on existing scientific evidence and expert advice $(1,16,17)$. Box 2 shows the eligibility guidelines and their operationalization based on the available information of the TOGETHER survey. In what is to follow, we discuss the criteria for which proxies were used.

Box 2: The MSM specific and high-risk group eligibility criteria adjusted to SSA migrants and operationalized by the TOGETHER data 


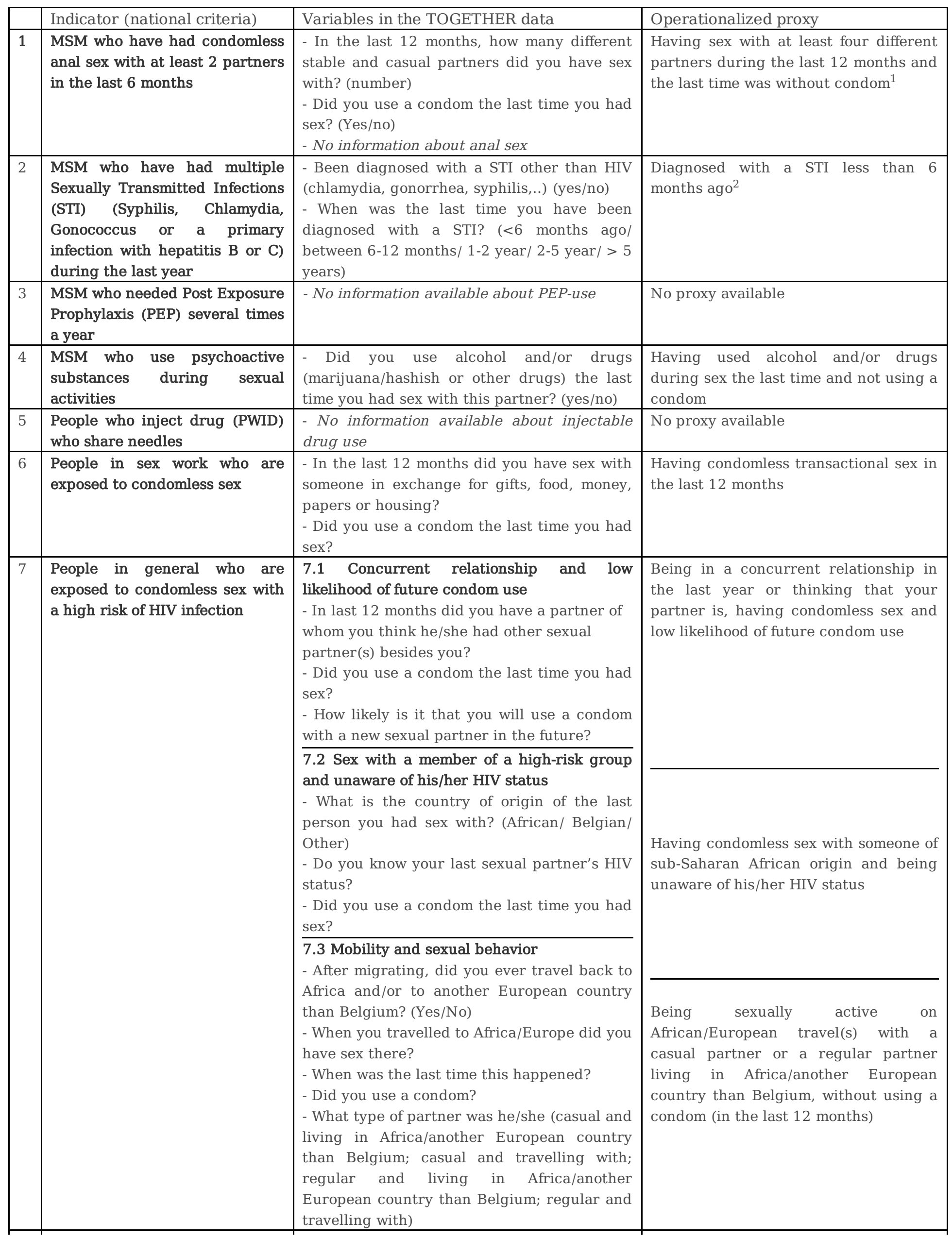

Page 5/19 
Notes: ${ }^{1}$ We have doubled the number of sexual partners, as the period is doubled (the number of sexual partners was asked for the last 12 months instead of 6 months) and we do not have information about anal sex.

2 The guidelines consider the number of STIs during last year, while in the TOGETHER study participants only reported about lifetime STI and time of occurrence. Therefore, the time period from 12 months was restricted to the last 6 months to operationalize a similar conservative measure.

3 Partners new on treatment or no viral suppression with adequate treatment

For the criterion 'People in sex-work and exposed to condomless sex' (eligibility criterion 6) we used the question about transactional sex (i.e. sex in exchange for gifts, food, money, papers or housing). In particular, young women living in and/or from SSA are known to engage in transactional sex as a way to make ends meet. It has been established as an important HIV risk factor among SSA migrants during and after settlement (16) and was found to be related to social and economic hardships (such as having an undocumented status) (16), which in turn are HIV vulnerability factors (18).

To operationalize eligibility criterion 7 'People in general who are exposed to condomless sex with a high risk of HIV infection' we rely on recent publications focusing on important risk factors among SSA migrants $(1,16,17)$. Three SSA migrant-specific factors (not yet covered by one of the other national criteria) were selected and they are counted as separate criteria. The first two risk factors (item 7.1 and 7.2) consider concurrency among SSA migrants and assortative sexual mixing (19), which is relevant in concentrated epidemics for HIV transmission. Preferences for African sexual partners, as well as concurrency within sexual networks where both high HIV prevalence of high rates of undiagnosed HIV elevating the risk of HIV transmission were established on the literature $(1,4,18,20)$. The first factor is operationalized as 'being in a concurrent partnership, having condomless sex and a low likelihood of future condom use (item 7.1). A social desirability bias when reporting condom use may occur, so PrEP should be considered for people reporting any intercourse without a condom or concerns about their future use of condoms (6). The second risk factor is operationalized as 'having condomless sex with an African partner of unknown HIV status' (item 7.2).

The third specific risk factor of interest to our target population is related to migrants' condomless sex during travelling abroad (eligibility criteria 7.3). Research showed that migrants' mobility was associated with increased risk for HIV infection (21) and that people of SSA origin traveled frequently both within Europe and to African home countries (1). Studies in Amsterdam (22), London (23), Antwerp and Lisbon (24) support the relation between migrants' mobility after settling and increased HIV risk. The latter study showed that SSA migrants who travel - in Europe or to Africa - are at increased risk for HIV, reporting more condomless sex and concurrency than nontravelers (24). Therefore we combined the following two items: 'travelled to an African country' and 'travelled to a European country'. The third criteria is thus measured as 'having condomless sex on African/European travel(s) with a casual or regular partner living in Africa/another European country than Belgium'.

\section{Study variables}

\section{Dependent variable}


The dichotomous variable 'being eligible to use PrEP (yes = 1; no $=0$ )' was operationalized as meeting at least one of the seven criteria - as presented in Box 2. Study subjects could have a missing value for maximum 3 out of 7 items. To get a better understanding of each HIV risk factor, the analyses were also done with the individual criteria as dependent dichotomous variables.

\section{Independent variables}

Socio-demographic variables included gender, age, sexual orientation, relationship status, country of origin, and migration duration $(2,4,18,20,25)$. Gender was a dichotomous variable (man/woman) and age was categorized in three age groups ' 18 to 30 years old', '31-40' and ' 41 or older'. Relationship status was combined with cohabitating with partner or not (single, in a relation and cohabiting, and in a relation and not cohabiting with this partner). For country of origin we categorized the countries in regions (Central, Western, Southern and Eastern), and Southern and Eastern Africa were taken together because of small percentages. Migration duration (or migration history) consisted of four categories: 1) not living in Belgium; 2) recently migrated (living in Belgium since less then2 years); 3) living in Belgium between 2 and 10 years; and 4) for more than 10 years or born in Belgium (second generation migrant). The variable MSM (yes/no) was constructed from the question 'in general, are the people you have sex with men, women or both?' whereby men who indicated to have sex with men or both men and women were labelled as MSM for our analyses.

In addition, socio-economic vulnerability was considered an independent variable, as previous research revealed a positive relation between socio-economic hardship and HIV-risk behaviour among migrants (25). Low or no educational level, unemployed or non-employed (retired, student, inactive due to disability), unstable housing, financial problems and being undocumented were considered as proxies for socio-economic vulnerability. They were measured by the categorical variable educational level (primary school or less, completed secondary, continued education); employment status ((self-) employed, un/non- employed, full time student); financial problems (no versus sometimes/most of the time); unstable housing (yes/no) and undocumented (yes/no). The latter was based on the question: 'Do you currently have health insurance?' and not having any kind of health insurance (Belgian welfare system, health coverage via asylum centre, health insurance in another European country or in an African country') was considered a proxy of being undocumented (1). Unstable housing included those who were homeless or living temporarily with friends. Finally, the variable 'forced sex" was considered a risk factor for HIV infection and measured by the question 'forced sex' (lifetime) (26).

\section{Analytic strategy}

In a first step, we examined potential associations between socio-demographic and -economic variables and the eligibility criteria (separately, combined with and without the SSA migrant-specific criteria) by bivariate statistics resulting in a contingency table and bivariate logistic regressions (Table I). Wald Chi-square tests were used to determine whether the associations between these categorical variables and the strength of the associations were measured by unadjusted (or crude) odds ratio's (OR). For all analyses, weighted data were used accounting for the unequal probability of selection according to Karon \& Wejnert (2012)(27) (venue attendance, study participation, and sampling fraction (1)). SSA migrants who visited sites more frequently had a higher probability of selection in

the study. Adjustment for this unequal selection probability was completed by calculating individual weights, based on the attendance (15).

Next, we performed multivariable logistic regression analyses with weighted data to investigate which factors were associated with 'being eligible to use PrEP', while controlling for confounding factors. Strengths of associations 
were measured using adjusted Odds Ratio and Wald Chi-square tests were applied to determine whether the individual coefficients of the regression were significant (with a $p$ value $<0,05$ considered statistically significant). We employed logistic regression models using a stepwise approach: to socio-demographic and migration related factors (Model 1) we added socio-economic factors (Model 2) and in the last step we also included the variable 'forced sex' (Model 3). The same models were also estimated for each eligibility criterion separately, but excluding the variables 'unstable housing', 'employment status' and 'migration duration' as these were not significant for any of the criteria. All the analyses were performed by the statistical software IBM SPSS statistics 26.

\section{Results}

Applying the exclusion criteria for this secondary analysis as described above resulted in a study sample of $n=686$ participants. About 3.3\% $(n=22)$ subjects had more than three missing values on the seven eligibility criteria and were subsequently excluded from the sample for the bivariate and multiple regression analyses $(n=664)$.

Graph 3 presents the weighted percentages of people with SSA migrant background in Antwerp who met the PrEP eligibility criteria (see the corresponding table A in appendix). In total, about $30.6 \%$ of them met at least one of the adapted criteria and thus were eligible to PrEP. If we exclude the three specific criteria $(7.1,7.2$ and 7.3$)$ only $17.7 \%$ of the sample were eligible for PrEP. The most frequent criterion was 'having condomless sex with someone of SSA origin and being unaware of his/her HIV status' (16.3\%), while a minority met the criterion 'diagnosed on a STI less than 6 months ago' (1.7\%).

\section{Graph 3}

Percentages of SSA migrants meeting the PrEP eligibility criteria

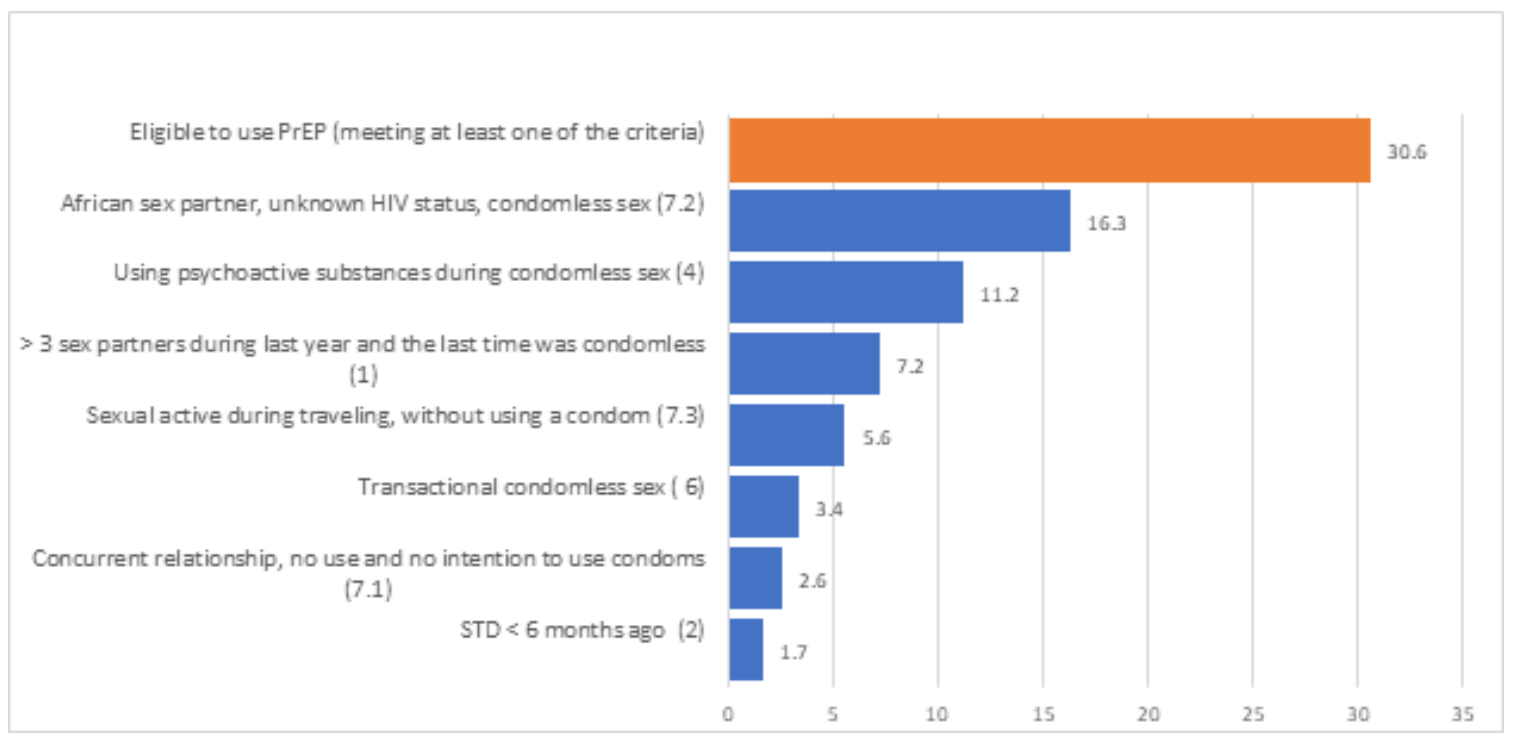

Among all HIV negative SSA migrants in our sample, $19,9 \%$ met only one criterion for PrEP eligibility, $7,4 \%$ met two criteria and $2,2 \%$ met three of them. The minority of SSA migrants meeting three or more criteria $(2,3 \% ; n=23$ out of $n=684$ ) were a selective and vulnerable group: almost half had no health insurance, thus being probably undocumented, most of them lived less than two years in Belgium, were not in a relationship and experienced financial difficulties.

The bivariate results (see Table 1) show that those who were eligible to use PrEP were significantly more likely to be male, MSM, single (versus in a relation and cohabiting) and reported having no health insurance than those who 
were ineligible. They were also more likely ever having experienced forced sex. 
Table 1

Factors associated with eligibility to PrEP in bivariate and multivariate analysis (weighted data)

\begin{tabular}{|c|c|c|c|c|c|c|c|c|c|c|c|}
\hline & \multicolumn{2}{|c|}{ Total } & \multirow{2}{*}{$\begin{array}{l}\% \\
\text { eligible }\end{array}$} & \multirow{2}{*}{$\begin{array}{l}\text { Un- } \\
\text { adjusted } \\
\text { OR }\end{array}$} & \multicolumn{3}{|c|}{$95 \%-\mathrm{Cl}$} & \multirow{2}{*}{$\begin{array}{l}\text { Adjusted } \\
\text { OR }\end{array}$} & \multicolumn{3}{|c|}{$95 \%-\mathrm{Cl}$} \\
\hline Variable ( $\mathrm{N}$ total) & $\mathrm{N}$ & $\%$ & & & & & & & & & \\
\hline Age & 664 & & & & & & & & & & \\
\hline $\begin{array}{l}\text { Between } 18- \\
30 \text { years old (ref.) }\end{array}$ & 239 & 36.05 & 30.33 & 1.00 & & & & 1.00 & & & \\
\hline $\begin{array}{l}\text { Between } 31- \\
40 \text { years old }\end{array}$ & 248 & 37.42 & 30.04 & 0.99 & 0.67 & 1.46 & & 1.33 & 0.83 & 2.15 & \\
\hline $\begin{array}{l}\text { Older than } \\
41 \text { years old }\end{array}$ & 176 & 26.53 & 31.07 & 1.09 & 0.72 & 1.66 & & 1.70 & 0.99 & 2.93 & \\
\hline Gender & 664 & & & & & & & & & & \\
\hline Women (ref.) & 423 & 63.78 & 25.51 & 1.00 & & & & 1.00 & & & \\
\hline Men & 240 & 36.22 & 32.95 & 1.38 & 0.97 & 1.97 & * & 1.65 & 1.09 & 2.50 & * \\
\hline MSM & 664 & & & & & & & & & & \\
\hline No MSM (ref.) & 651 & 98.07 & 29.76 & 1.00 & & & & 1.00 & & & \\
\hline MSM & 13 & 1.93 & 61.54 & 3.62 & 1.16 & 11.25 & * & 2.58 & 0.74 & 8.97 & \\
\hline Relation status & 664 & & & & & & & & & & \\
\hline $\begin{array}{l}\text { Not in a } \\
\text { relationship (ref.) }\end{array}$ & 259 & 39.01 & 34.35 & 1.00 & & & & 1.00 & & & \\
\hline $\begin{array}{l}\text { In a relation and } \\
\text { cohabiting }\end{array}$ & 284 & 42.83 & 24.14 & 0.60 & 0.41 & 0.87 & ** & 0.56 & 0.35 & 0.88 & * \\
\hline $\begin{array}{l}\text { In a relation and } \\
\text { not cohabiting }\end{array}$ & 120 & 18.16 & 36.59 & 1.08 & 0.69 & 1.70 & & 1.05 & 0.62 & 1.76 & \\
\hline $\begin{array}{l}\text { Country of Origin } \\
\text { (region) }\end{array}$ & 664 & & & & & & & & & & \\
\hline $\begin{array}{l}\text { Western Africa } \\
\text { (ref.) }\end{array}$ & 444 & 66.97 & 28.89 & 1.00 & & & & 1.00 & & & \\
\hline Central Africa & 180 & 27.14 & 30.98 & 1.08 & 0.74 & 1.57 & & 1.55 & 1.00 & 2.40 & * \\
\hline $\begin{array}{l}\text { Southern or } \\
\text { Eastern Africa }\end{array}$ & 39 & 5.89 & 45.00 & 1.89 & 0.98 & 3.68 & a & 2.12 & 0.99 & 4.54 & a \\
\hline $\begin{array}{l}\text { Migration } \\
\text { duration }\end{array}$ & 656 & & & & & & & & & & \\
\hline
\end{tabular}

${ }^{*} p<0,05{ }^{* *} p<0,01 * * * p<0,001 ;$ ref. = reference category; $n=664$ for the logistic regression analyses

(a) operationalized by the proxy 'no health insurance' 


\begin{tabular}{|c|c|c|c|c|c|c|c|c|c|c|c|}
\hline & Total & & $\%$ & $\begin{array}{l}\text { Un- } \\
\text { adjusted }\end{array}$ & $95 \%-C$ & & & Adjusted & $95 \%-C$ & & \\
\hline $\begin{array}{l}\text { Living in Belgium } \\
\text { for more than } \\
10 \text { years (or born) } \\
\text { (ref.) }\end{array}$ & 237 & 35.7 & 31.10 & 1.00 & & & & 1.00 & & & \\
\hline $\begin{array}{l}\text { Not living in } \\
\text { Belgium }\end{array}$ & 37 & 5.65 & 21.60 & 0.63 & 0.28 & 1.43 & & 0.61 & 0.23 & 1.62 & \\
\hline $\begin{array}{l}\text { Living in Belgium } \\
\text { since < } 2 \text { years }\end{array}$ & 149 & 22.52 & 32.90 & 1.08 & 0.70 & 1.68 & & 1.01 & 0.57 & 1.76 & \\
\hline $\begin{array}{l}\text { Living in Belgium } \\
\text { for } 2-10 \text { years }\end{array}$ & 232 & 34.95 & 29.30 & 0.92 & 0.62 & 1.36 & & 0.85 & 0.54 & 1.35 & \\
\hline Legal status $^{\mathrm{a}}$ & 663 & & & & & & & & & & \\
\hline $\begin{array}{l}\text { Documented } \\
\text { (ref.) }\end{array}$ & 518 & 78.12 & 28.00 & 1.00 & & & & 1.00 & & & \\
\hline $\begin{array}{l}\text { Probably } \\
\text { undocumented }\end{array}$ & 145 & 21.79 & 40.00 & 1.72 & 1.17 & 2.52 & * & 1.83 & 1.12 & 2.99 & * \\
\hline Education & 645 & & & & & & & & & & \\
\hline $\begin{array}{l}\text { Primary school or } \\
\text { less (ref.) }\end{array}$ & 101 & 15.18 & 34.00 & 1.00 & & & & 1.00 & & & \\
\hline $\begin{array}{l}\text { Completed } \\
\text { secondary }\end{array}$ & 313 & 47.18 & 33.50 & 0.98 & 0.61 & 1.57 & & 0.99 & 0.58 & 1.67 & \\
\hline $\begin{array}{l}\text { Continued } \\
\text { education }\end{array}$ & 231 & 34.86 & 26.20 & 0.70 & 0.42 & 1.15 & & 0.56 & 0.31 & 1.00 & * \\
\hline Employment & 664 & & & & & & & & & & \\
\hline (Self)employed & 317 & 47.78 & 29.90 & & & & & & & & \\
\hline $\begin{array}{l}\text { Unemployed/non- } \\
\text { employed }\end{array}$ & 288 & 43.41 & 32.60 & 1.14 & 0.81 & 1.61 & & 0.81 & 0.52 & 1.24 & \\
\hline Full time student & 58 & 8.81 & 24.10 & 0.77 & 0.40 & 1.46 & & 0.80 & 0.37 & 1.70 & \\
\hline $\begin{array}{l}\text { Financial } \\
\text { problems }\end{array}$ & 625 & & & & & & & & & & \\
\hline No (ref.) & 228 & 34.30 & 26.80 & 1.00 & & & & 1.00 & & & \\
\hline $\begin{array}{l}\text { Sometimes/most } \\
\text { of the time }\end{array}$ & 397 & 59.86 & 33.50 & 1.39 & 0.97 & 1.99 & $a$ & 1.23 & 0.82 & 1.84 & \\
\hline Housing & 636 & & & & & & & & & & \\
\hline Stable (ref.) & 595 & 89.69 & 30.60 & 1.00 & & & & 1.00 & & & \\
\hline Unstable & 41 & 6.13 & 40.00 & 1.54 & 0.80 & 2.94 & & 1.35 & 0.61 & 2.99 & \\
\hline \multicolumn{12}{|c|}{$\star_{p}<0,05 * *_{p}<0,01 * * * p<0,001 ;$ ref. $=$ reference category; $n=664$ for the logistic regression analyses } \\
\hline
\end{tabular}




\begin{tabular}{|c|c|c|c|c|c|c|c|c|c|c|c|}
\hline & \multicolumn{2}{|c|}{ Total } & $\%$ & $\begin{array}{l}\text { Un- } \\
\text { adjusted }\end{array}$ & \multicolumn{3}{|c|}{$95 \%-\mathrm{Cl}$} & \multirow[t]{2}{*}{ Adjusted } & \multicolumn{3}{|c|}{$95 \%-\mathrm{Cl}$} \\
\hline $\begin{array}{l}\text { Forced sex } \\
\text { (lifetime) }\end{array}$ & \multicolumn{10}{|l|}{664} & \\
\hline Never (ref.) & 620 & 93.44 & 29.40 & 1.00 & & & & 1.00 & & & \\
\hline Ever & 44 & 6.56 & 47.70 & 2.21 & 1.19 & 4.11 & ** & 2.10 & 1.01 & 4.39 & , \\
\hline \multicolumn{12}{|c|}{${ }^{*} p<0,05 * * p<0,01 * * * p<0,001 ;$ ref. $=$ reference category; $n=664$ for the logistic regression analyses } \\
\hline
\end{tabular}

For the multivariate logistic regression analyses, there were no large differences between the results of Model 1, 2 and 3 when adding the socio-economic and forced sex variables. Therefore, only Model 3 is presented in Table 1 (adjusted ORs): Men, those without a relationship, those without health insurance, and who ever had experienced forced sex were more likely to be eligible for PrEP than women, those in a relationship and co-habiting, with health insurance, and those who had not experienced forced sex. Being MSM was no longer significantly associated with 'being eligible to PrEP use' when controlling for the other variables in the model. Educational level and region of origin became significantly associated to PrEP eligibility. Participants with only primary or no education and those from Central-Africa were more likely to meet one of the eligibility criteria when compared with those with vocational or university education (continued education) and people originating from Western Africa.

The results of the logistic regression analyses for the separate criteria did not change during the stepwise procedure. The third model is presented in Table B of the Appendix in addition to the unadjusted ORs.

SSA migrants without health insurance were more likely to have four or more sex partners and to report condomless sex. Without controlling for the other variables they were also more likely to report condomless transactional sex. Male SSA migrants reporting same sex behaviour (MSM) also had a higher likelihood of transactional condomless sex and of being in a concurrent relationship with condomless sex and low likelihood of condom use in the future, also after taking the other variables into account.

SSA migrants of the age-group between 31 to 40 years, from Central, Southern or Eastern Africa, or experiencing economic hardship, were more likely to take drugs and/or alcohol while having condomless sex compared to younger SSA migrants, SSA migrants from Western Africa and SSA migrants without economic hardship. Taking the other variables into account, SSA migrants older than 40 were more likely to have had a STI during the last six months, to have reported condomless sex during travelling and condomless sex with a partner of African origin without knowing his/her HIV status, but they were less likely to had four or more sexual partners the last 12 months compared to the youngest age group (below 30 years of age).

In a sensitivity analysis, the control variable study setting was included. Study setting is a categorical variable consisting of 4 categories: bar/party of African organization, church, public place (park, street, square), meeting of African organization, and other (shop, hair salon, library, asylum center). This variable had no significant effect on the eligibility to PrEP and taking this control variable info account did not change the other effects.

\section{Discussion}


This study is among the first to assess the eligibility to use PrEP among SSA migrants, residing in Belgium (Antwerp). Although only a few people with a SSA migration background use PrEP in Belgium, we have estimated that almost a third is eligible to use PrEP. To the best our knowledge it is also the first study in Europe to quantify PrEP need among a mainly heterosexual population with migration background, in this case of SSA origin.

We found that $30.6 \%$ of the respondents were eligible to use PrEP. Those who were male, single, lower educated, without health insurance (thus likely of undocumented status), and those who had experienced forced sex were more likely to be eligible for PrEP use. Hence, a combination of factors at the individual, the interpersonal and the structural level may shape HIV risk accounting for PrEP eligibility. This shows the significant role of multi-level social determinants of health, including migration, as found in other studies (10). The high estimation of roughly $30 \%$ in our sample eligible for PrEP in contrast with the low number of people of SSA migration background actually taking PrEP in Belgium raises concerns about a potential large PrEP gap among this population.

The majority of those eligible for PrEP was meeting one or two eligibility criteria. However, a selective and vulnerable minority has three or more HIV risk factors: almost half had no health insurance, most of them lived less than two years in Belgium and experienced financial difficulties. Therefore, utmost attention should be paid to structural vulnerability such as having no health insurance or being undocumented. When people do not have any health insurance, they face a double risk. Due to their increased HIV risk, they have a higher need for PrEP, while at the same time access to and reimbursement of PrEP is more difficult, similar to the access of other HIV care services (38).

Adding interpersonal and network-level risk factors for PrEP elibility (12), such as having sex with people of African origin, concurrent relationships and sex during travelling after migration in Europe and Africa $(1,28)$ increased the proportion of people with SSA migration background eligible for PrEP from $18 \%$ to $30.6 \%$. This shows that it is important to consider target-group specific factors accounting for HIV risk when assessing PrEP need. PrEP is the most cost-effective (29) and has the highest impact on HIV prevalence (30) when those at highest risk of HIV exposure are identified and prioritized as potential PrEP users.

Our study highlights the role of several relevant predictors for PrEP eligibility. In what is to follow, we discuss the most important ones.

Respondents were more likely to be eligible for PrEP when they were male, single, had lower educational attainment, no health insurance, originated from Central, Southern and Eastern Africa, and had experienced forced sex. Several of these observations were in line with existing research on HIV vulnerability among SSA migrants $(2,3,25)$. Having no education or less than primary education and having no health insurance was related to a higher likelihood of being eligible for PrEP use, and SSA migrants who have financial problems had a higher chance of having condomless sex while taking psychoactive substances.

Our findings also highlight the role of intersecting vulnerabilities in shaping HIV risk and PrEP need: although the number of men having sex with men was limited in our sample $(n=13)$, more than half of them were eligible to use $\operatorname{PrEP}(n=8)$. This reflects their high risk of HIV, and it is corroborated by the fact that the majority of the few people with SSA migrant background who already use PrEP are MSM, according to the Belgian HIV surveillance (31). American research (34) reveals lower proportions of black MSM being eligible for PrEP based on the clinical criteria. They argue that this finding can be ascribed to the fact that the standardized clinical criteria are not sensitive to the risk factors among the black community, which is a concern that could also be raised about the Belgian guidelines. Our results also show that the subgroup of MSM reported more transactional condomless sex; were more often in a 
concurrent relationship having condomless sex; and reported lower condom use intentions compared to heterosexual men. As this sub-group belongs to both a sexual and an ethnic minority group confronted with multiple levels of stigma (32), they may require a targeted prevention approach.

\section{Limitations}

Using an existing database comes with inherent limitations: we were unable to directly measure each criterion of the Belgian PrEP eligibility criteria (e.g. injecting drugs). Lack of these data might have resulted in an underestimation of the percentage of SSA migrants eligible to use PrEP. Self-reported and retrospective data may led to underreporting of sensitive subjects (e.g. condomless sex) and be subject to recall bias. Data collection was limited to the city of Antwerp and may therefore the results have limited generalizability.

\section{Conclusions}

In spite of these limitations, our findings enable us to draw a number of relevant recommendations for clinical practice and public health policy.

Based on our findings, we argue that the eligibility criteria in Belgium, and by extension in other countries, should include target-group specific risk factors, to increase the likelihood to detect unmet PrEP needs and enable these groups to start PrEP.

However, PrEP eligibility does not equal the willingness or intention to use PreP and as a consequence PrEP uptake (33). We need to better understand the existing barriers for PrEP use within this population, and to develop tailored ways to upscale PrEP use for those in need as part of a combination prevention strategy. Until now PrEP has been mostly been framed as a prevention method for MSM at high risk of HIV acquisition (11), while qualitative research has shown that among African communities it is often less known or perceived as a method for people with "promiscuous" sexual behavior (34).

Our results underscore the recommendations from research on black MSM in the US $(12,35)$. To destigmatize PrEP and to reduce inequality in access to it, PrEP should be integrated into routine preventive health and primary care. Making PrEP available independent of health care coverage could be an option to increase access in Belgium, in analogy with HIV treatment. Discussing PrEP with all patients will reframe PrEP as sexual health promotion tool, irrespective of gender, sexual orientation, relationship status or ethnicity (12). This way, unsensitive eligibility criteria and their implementation may be avoided, thus missing less potential PrEP candidates, above helping health care providers to raise the topic of HIV prevention without feeling uncomfortable or being stigmatizing.

In addition, our findings provide valuable insights into PrEP screening for specific sub-groups within our target population, such as men with same sex behavior. The pre-established criteria seem not to be sufficient to capture the social and structural risk factors driving the HIV epidemic in this community. Accounting for the predictors at multiple levels, individual risk factors should be explored against the context of structural vulnerabilities. Screening questions aiming at revealing only individual sexual risk behaviors therefore may not pick up this vulnerability. In analogy with HIV testing $(18,37)$, more comprehensive guidance including culturally competent phrasing of screening questions should be developed.

Risk factors and the level of risk may also be dynamic over time (24)(34). Likewise PrEP need and eligibility can change related to life stages, residence status, relationship periods and their socio-economic environment. This can

Page 14/19 
be relevant in relation to mobility, where the likelihood of concurrent sexual relationships while traveling may be higher. Again, this highlights the importance of assessing such 'seasons of risk' during screening and providing PrEP alongside other appropriate interventions for a limited duration (34). Time-limited use of PrEP and use related to specific situations and contexts may also have a positive impact on the accessibility and destigmatization of PrEP (34).

To conclude, the combination of a high proportion of people with SSA migration background who are eligible for PrEP use while almost none of them is currently using PrEP raises concerns about the effective implementation of PrEP among this population in Belgium. Future studies should inform evidence-based interventions to address the barriers to PrEP use at individual, community, and structural levels to achieve equitable access.

\section{Abbreviations}

PrEP: Pre-Exposure Prophylaxis

HIV: Human Immunodeficiency Virus

SSA: Sub-Saharan African

MSM: Men who have Sex with Men

STIs: Sexually Transmitted Infections

PEP: Post Exposure Prophylaxis

PWID: People Who Inject Drugs

PLWH: Partners of people Living With HIV

OR: Odds Ratio

Cl: Confidence Interval

Ref.: Reference category

\section{Declarations}

\section{Ethics approval and consent to participate}

Ethical approval for the TOGETHER project was obtained from the Institutional Review Board of the Institute of Tropical Medicine and the ethical committee of the University Hospital Antwerp. To be eligible, potential study participants had to be willing and able to provide written informed consent. More information can be find in the protocol paper of the TOGETHER project [15].

\section{Consent for publication}

Not applicable

\section{Availability of data and materials}


The data that support the findings of this study are available from the TOGETHER Project of the Institute of Tropical Medicine (Antwerp, Belgium) but restrictions apply to the availability of these data, which were used under license for the current study, and so are not publicly available. Data are however available from the authors upon reasonable request and with permission of the Institute of Tropical Medicine.

\section{Competing interests}

None declared.

\section{Funding}

This study is part of the Promise project 'Optimise PrEP to Maximise Impact', funded by FWO-SBO (Flemish Scientific Research - Strategic Basic Research). The overall objective of this project is to learn how PrEP rollout can be optimized to result in maximum impact on HIV and sexual health.

The data used stem from the TOGETHER project, which was funded by the Scientific Fund for Research on AIDS, managed by the King Baudouin Foundation, Belgium.

\section{Authors' contributions}

Study concept and design: VB, CN, CM, EW and BV. Analysis and interpretation of data: VB. Drafting of the manuscript: VB. Critical revision of the manuscript for important intellectual content: EvL, TR, CN, CM, EW and BV. Study supervision: EW, CN and BV. All authors read and approved the final manuscript.

\section{References}

1. Loos J, Nostlinger C, Vuylsteke B, Deblonde J, Ndungu M, Kint I, et al. First HIV prevalence estimates of a representative sample of adult sub-Saharan African migrants in a European city. Results of a communitybased, cross-sectional study in Antwerp, Belgium. Plos One. 2017;12(4). e0174677.https://doi.org/10.1371/journal.pone.0174677

2. Desgrees-du-Lou A, Pannetier J, Ravalihasy A, Gosselin A, Supervie V, Panjo H, et al. Sub-Saharan African migrants living with HIV acquired after migration, France, ANRS PARCOURS study, 2012 to 2013. Eurosurveillance. 2015;20(46):31-8.

3. Desgrees-du-Lou A, Pannetier J, Ravalihasy A, Le Guen M, Gosselin A, Panjo H, et al. Is hardship during migration a determinant of HIV infection? Results from the ANRS PARCOURS study of sub-Saharan African migrants in France. Aids. 2016;30(4):645-56.

4. Alvarez-del Arco D, Fakoya I, Thomadakis C, Pantazis N, Touloumi G, Gennotte AF, et al. High levels of postmigration HIV acquisition within nine European countries. Aids. 2017;31(14):1979-88.

5. WHO. Implementation tool for pre-exposure prophylaxis (PrEP) of HIV infection. Module 5: Monitoring and evaluation. Geneva: World Health Organization; 2018 (WHO/CDS/HIV/18.10). Licence: CC BY-NC-SA 3.0 IGO.

6. WHO. Implementation tool for pre-exposure prophylaxis (PrEP) of HIV infection. Module 1: Clinical.. Geneva: World Health Organization;; 2017. https://apps.who.int/iris/handle/10665/255889. License: CC BY-NC-SA 3.0 IGO

7. Sciensano. Data from the HIV Reference Centres, June 2017 - December 2018. Presented at 'BREACH'. 2019. 
8. Vuylsteke B, Reyniers T, Lucet C, Nostlinger C, Deblonde J, Libois A, et al. High uptake of pre-exposure prophylaxis (PrEP) during early roll-out in Belgium: results from surveillance reports. Sex Health. 2019;16(1):803.

9. Gosselin A, Carillon S, Coulibaly K, Ridde V, Taeron C, Kohou V, et al. Participatory development and pilot testing of the Makasi intervention: a community-based outreach intervention to improve sub-Saharan and Caribbean immigrants' empowerment in sexual health. Bmc Public Health. 2019;19(1):1646.

10. Annequin M, Villes V, Delabre RM, Alain T, Morel S, Michels D, et al. Are PrEP services in France reaching all those exposed to HIV who want to take PrEP? MSM respondents who are eligible but not using PrEP (EMIS 2017). Aids Care. 2020.

11. Loos J, Nostlinger C, Reyniers T, Colebunders R, Jespers V, Manirankunda L, et al. PrEP for African migrants in Europe? A research agenda. Lancet HIV. 2016;3(11):e505-e7.

12. Calabrese SK, Krakower DS, Mayer KH. Integrating HIV Preexposure Prophylaxis (PrEP) Into Routine Preventive Health Care to Avoid Exacerbating Disparities. Am J Public Health. 2017;107(12):1883-9.

13. Young I, Flowers P, McDaid LM. Barriers to uptake and use of pre-exposure prophylaxis (PrEP) among communities most affected by HIV in the UK: findings from a qualitative study in Scotland. Bmj Open. 2014;4(11).

14. Aaron E, Blum C, Seidman D, Hoyt MJ, Simone J, Sullivan M, et al. Optimizing Delivery of HIV Preexposure Prophylaxis for Women in the United States. Aids Patient Care St. 2018;32(1):16-23.

15. Loos J, Vuylsteke B, Manirankunda L, Deblonde J, Kint I, Namanya F, et al. TOGETHER Project to Increase Understanding of the HIV Epidemic Among Sub-Saharan African Migrants: Protocol of Community-Based Participatory Mixed-Method Studies. JMIR Res Protoc. 2016;5(1):e48.

16. Gosselin A, Ravalihasy A, Pannetier J, Lert F, Desgrées du Loû A. When and why? Timing of post-migration HIV acquisition among sub-Saharan migrants in France. Sex Transm Infect. 2019:sextrans-2019-054080.

17. Dias S, Loos J, Roxo L, Gama A, Simoes D, Noestlinger C. Understanding the links between mobility, risky sexual behaviors and HIV among sub-Saharan African migrants (SAMs): a study in two European cities. European Journal of Public Health. 2018;28:82-.

18. Alvarez-del Arco D, Monge S, Azcoaga A, Rio I, Hernando V, Gonzalez C, et al. HIV testing and counselling for migrant populations living in high-income countries: a systematic review. Eur J Public Health. 2013;23(6):103945 .

19. Fakoya I, Alvarez-del Arco D, Woode-Owusu M, Monge S, Rivero-Montesdeoca Y, Delpech V, et al. A systematic review of post-migration acquisition of HIV among migrants from countries with generalised HIV epidemics living in Europe: mplications for effectively managing HIV prevention programmes and policy. Bmc Public Health. 2015;15.

20. Brannstrom J, Sonnerborg A, Svedhem V, Neogi U, Marrone G. A high rate of HIV-1 acquisition post immigration among migrants in Sweden determined by a CD4 T-cell decline trajectory model. Hiv Med. 2017;18(9):677-84.

21. Davies AA, Basten A, Frattini C. Migration: a social determinant of the health of migrants. Eurohealth (Lond). 2009;16(1):10-2.

22. Kramer MA, van den Hoek A, Coutinho RA, Prins M. Sexual risk behaviour among Surinamese and Antillean migrants travelling to their countries of origin. Sex Transm Infect. 2005;81(6):508-10.

23. Fenton KA, Chinouya M, Davidson O, Copas A, Team MR. HIV transmission risk among sub-Saharan Africans in London travelling to their countries of origin. Aids. 2001;15(11):1442-5. 
24. Dias S, Gama A, Loos J, Roxo L, Simoes D, Nostlinger C. The role of mobility in sexual risk behaviour and HIV acquisition among sub-Saharan African migrants residing in two European cities. Plos One. 2020;15(2):e0228584.

25. Dias S, Marques A, Gama A, Martins MO. HIV Risky Sexual Behaviors and HIV Infection Among Immigrants: A Cross-Sectional Study in Lisbon, Portugal. Int J Env Res Pub He. 2014;11(8):8552-66.

26. Desgrees-du-Lou A, Pannetier J, Ravalihasy A, Le Guen M, Gosselin A, Panjo H, et al. Is hardship during migration a determinant of HIV infection? Results from the ANRS PARCOURS study of sub-Saharan African migrants in France. Aids. 2016;30(4):645-56.

27. Karon JM, Wejnert C. Statistical Methods for the Analysis of Time-Location Sampling Data. J Urban Health. 2012;89(3):565-86.

28. Loos J, Nostlinger C, Vuylsteke B, Deblonde J, Ndungu M, Kint I, et al. First HIV prevalence estimates of a representative sample of adult sub-Saharan African migrants in a European city. Results of a communitybased, cross-sectional study in Antwerp, Belgium. Plos One. 2017;12(4):e0174677.

29. Hankins C, Macklin R, Warren M. Translating PrEP effectiveness into public health impact: key considerations for decision-makers on cost-effectiveness, price, regulatory issues, distributive justice and advocacy for access. J Int Aids Soc. 2015;18:71-7.

30. Rozhnova G, Heijne J, Bezemer D, van Sighem A, Presanis A, De Angelis D, et al. Elimination prospects of the Dutch HIV epidemic among men who have sex with men in the era of preexposure prophylaxis. Aids. 2018;32(17):2615-23.

31. Sciensano. HIV numbers 2020 [Available from: https://www.sciensano.be/en/health-topics/hiv-andaids/numbers.

32. Dodds C, Sesay M, Gillgower W. The Knowledge, the Will and the Power, A plan of action to meet the HIV prevention needs of Africans living in England, : Sigma research; 2008.

33. Rendina HJ, Whitfield THF, Grov C, Starks TJ, Parsons JT. Distinguishing hypothetical willingness from behavioral intentions to initiate HIV pre-exposure prophylaxis (PrEP): Findings from a large cohort of gay and bisexual men in the US. Soc Sci Med. 2017;172:115-23.

34. Mugo NR, Ngure K, Kiragu M, Irungu E, Nduku K. PrEP for Africa: What we have learnt and what is needed to move to program implementation. Curr Opin Hiv Aids. 2016;11(1):80-6.

35. Hoots BE, Finlayson T, Nerlander L, Paz-Bailey G, Study NHBS. Willingness to Take, Use of, and Indications for Pre-exposure Prophylaxis Among Men Who Have Sex With Men-20 US Cities, 2014. Clin Infect Dis. 2016;63(5):672-7.

36. Fenton KA, Chinouya M, Davidson O, Copas A, Team MS. HIV testing and high risk sexual behaviour among London's migrant African communities: a participatory research study. Sex Transm Infect. 2002;78(4):241-5.

37. Loos J, Manirankunda L, Hendrickx K, Remmen R, Nostlinger C. Hiv Testing in Primary Care: Feasibility and Acceptability of Provider Initiated Hiv Testing and Counseling for Sub-Saharan African Migrants. Aids Education and Prevention. 2014;26(1):81-93.

\section{Supplementary Files}

This is a list of supplementary files associated with this preprint. Click to download. 
- ADDITIONALFILES.docx

Page 19/19 